\title{
3D-Printed Model Enhances Learning Experience in Optometric Education
}

\author{
Mohd Zulfaezal Che Azemin, Mohd Afiq Ariffin Azman, Muhammad Hafizuddin Bahrain, \\ Mohd Izzuddin Mohd Tamrin
}

\begin{abstract}
Three-dimensional (3D) printed model becomes more popular as the flexibility to print $3 D$ model has become cheaper to produce. This research sought to assess the effect of using 3D printed model as a tool in teaching on optometry students. Another primary focus of this research was to assess the confidence level and enjoyment level among the second-year optometry students on traditional lecture method and compared it with the use of $3 D$ printed model as a teaching aid. Confidence is important as an optometrist, especially when making the right clinical judgement. Enjoyment is also important as it may help learning process become effective and fast. A total of 36 second-year optometry students were selected to participate in this research. The $3 D$ printed model was based on ophthalmoscope that had been printed using PRUSA $30003 D$ printer. The students were divided into two groups - one group was exposed to the lecture only and another group was exposed to $3 D$ model in addition to the traditional lecture. Two sets of questionnaires were given to assess their confidence and enjoyment level before and after each learning session. The confidence level assessment and the enjoyment level comprise of three statements on each topic answered by the students using 5-point Likert scale. The results showed that there are significance differences between lecture only group and lecture with 3D-printed model group especially as a visualization tool $(P$ $=0.001)$ and it is considered to be enjoyable and stimulating $(P=$ 0.008 ). This study demonstrates that the usage of $3 D$ printed model as teaching aid does affect the confidence level and enjoyment level of students.
\end{abstract}

Index Terms: 3D-Printed Model, Biomedical Engineering.

\section{INTRODUCTION}

Three-dimensional (3D) printing, also known as additive manufacturing is a technology which was first emerged in engineering that produces $3 \mathrm{D}$ objects through a process of adding layer upon layer of materials, based upon a virtual or computer-generated model to produce models at a reduced cost.

An object can be created directly from computer model by process of layering in constructing the model. The 3D data from the computer undergoes a slicing algorithm to generate detailed information for every layer. The model is then subjected to a process called fused deposition modelling

Revised Manuscript Received on July 12, 2019

Mohd Zulfaezal Che Azemin, Kulliyyah of Allied Health Sciences, International Islamic University, Kuantan, Malaysia.

Mohd Afiq Ariffin Azman, Kulliyyah of Allied Health Sciences, International Islamic University Malaysia, Kuantan, Malaysia.

Muhammad Hafizuddin Bahrain, Kulliyyah of Allied Health Sciences, International Islamic University Malaysia, Kuantan, Malaysia.

Mohd Izzuddin Mohd Tamrin, Kulliyyah of Information and Communication Technology, International Islamic University Malaysia, Gombak, Malaysia.
(FDM), a process of extruding acrylonitrile butadiene styrene (ABS) filament through a heating element, which turns the ABS filament into semi-molten state. The semi-molten ABS pass through a nozzle and it is deposited onto partially constructed part. The nozzle moves in $\mathrm{x}-\mathrm{y}$ plane according to the model created. The platform moves vertically downward along z-plane to deposit a new layer on the top of the previous layer. After a period of time, the layers of ABS deposit become full physical 3D object.

Malaysia shows a sharp growth in the number of tertiary students (Lee, 2002). The effectiveness of education emphasizes on the study time spent on the educational or examination programme (Van den Berg \& Hofman, 2005). The time spent on study peaks just before an examination. Besides that, student will focus on examination that scheduled earlier compared to examination that scheduled later. These few examples signify that there are many factors that can affect students' performance.

3D-printed model has been used for teaching aid for example in hospital, 3D printed model was used to visualize patients' kidneys to see their tumor location and educate them about basic kidney anatomy. The patient's understanding on basic kidney anatomy was significantly improved after the introduction to 3D-printed kidney model (Bernhard et al., 2016). It has also been used to educate on aortic arch obstruction whereby the doctor would use 3D-printed model of hearts for simulation of procedure to patients and their family members (Kiraly et al., 2015). 3D-printed model also has been implemented in surgical training such as in neurosurgical training (Waran et al., 2013)

In another study, 3D-printed structure has shown to assist medical students to identify anatomical structure of human lower limb. The 3D-printed lower limb is comparable to cadaveric based teaching with low cost of production (Heng $\mathrm{K}$. et al. 2016). It is predicted that it will become essential instrument in the next 5-10 years (Oreilly M .K. et al., 2016). Besides that, confidence level of the student by using 3D-printed model is significantly higher compared to textbook and simulation (Preece et al., 2013) (Al-Ramahi J. et al., 2016).

The usage of 3D-printed model is increasing steadily especially in education and medical field. The low-cost of production of 3D-printed model is one of the reasons the usage of 3D-printed model increase. In addition, the availability of some resources for educational purposes are limited, such as cadaver in anatomical study as opposed 


\section{D-Printed Model Enhances Learning Experience in Optometric Education}

to the 3D-printed model which is easily reproducible, allowing more immersive education.

There is little research on 3D printed model in Malaysia especially on optometry students, hence, further research on this technology is warranted to explore its potential in our education system. This study aims to evaluate and compare the confidence and enjoyment levels of undergraduate optometry students. This study is important to support other researches that claim learning with 3D-printed model shows higher confidence level and enjoyment level compared to conventional method of lectures.

\section{METHODOLOGY}

This study is an experimental study where the researcher manipulates independent variable which is the 3D model ophthalmoscope used as tool for education to see whether there was changes of confidence and enjoyment level compared to typical lecture only.

Thirty-six participants were recruited among second year optometry students in session 2017/2018 through a convenience sampling. The participation inclusion criteria for this study were the student must be a second year IIUM undergraduate optometry students in session 2017/2018 and the students must have attended for lecture in a designated topic which are "Ophthalmoscopy" in "Instrumentation Optometry" course.

The following are the materials used in this research:

- 3D Printer PRUSA 3000

- Acrylonitrile-butadiene-styrene (ABS) plastic

- Laptop

- 20D Volks Lens

- 8 sets of N3/N8 bolts and nuts

- A smartphone with rear camera and rear flash light

- $\quad$ Eye model

The 3D model that used in this study was a fundoscopy, designed by oDocs Eye Care. There were seven parts of 3D model that need to be assembled by eight sets of $\mathrm{N} 3$ bolts and nuts and a set of N8 bolt and nut as shown in Figure 1.

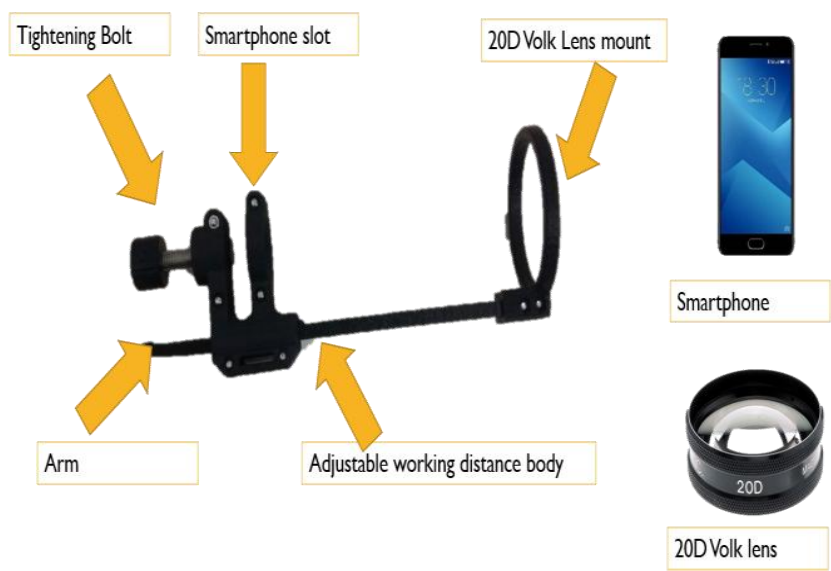

Fig. 1. 3D-printed fundosopy based on oDocs Fundus design (http://www.odocs-tech.com)
The 3D model was printed by using PRUSA 3000 by using ABS plastic. The bed of the printer and its extruder were heated at $100^{\circ} \mathrm{C}$ and $300^{\circ} \mathrm{C}$ respectively before printing the $3 \mathrm{D}$ model. Figure 2 summarizes the procedure employed in this work.

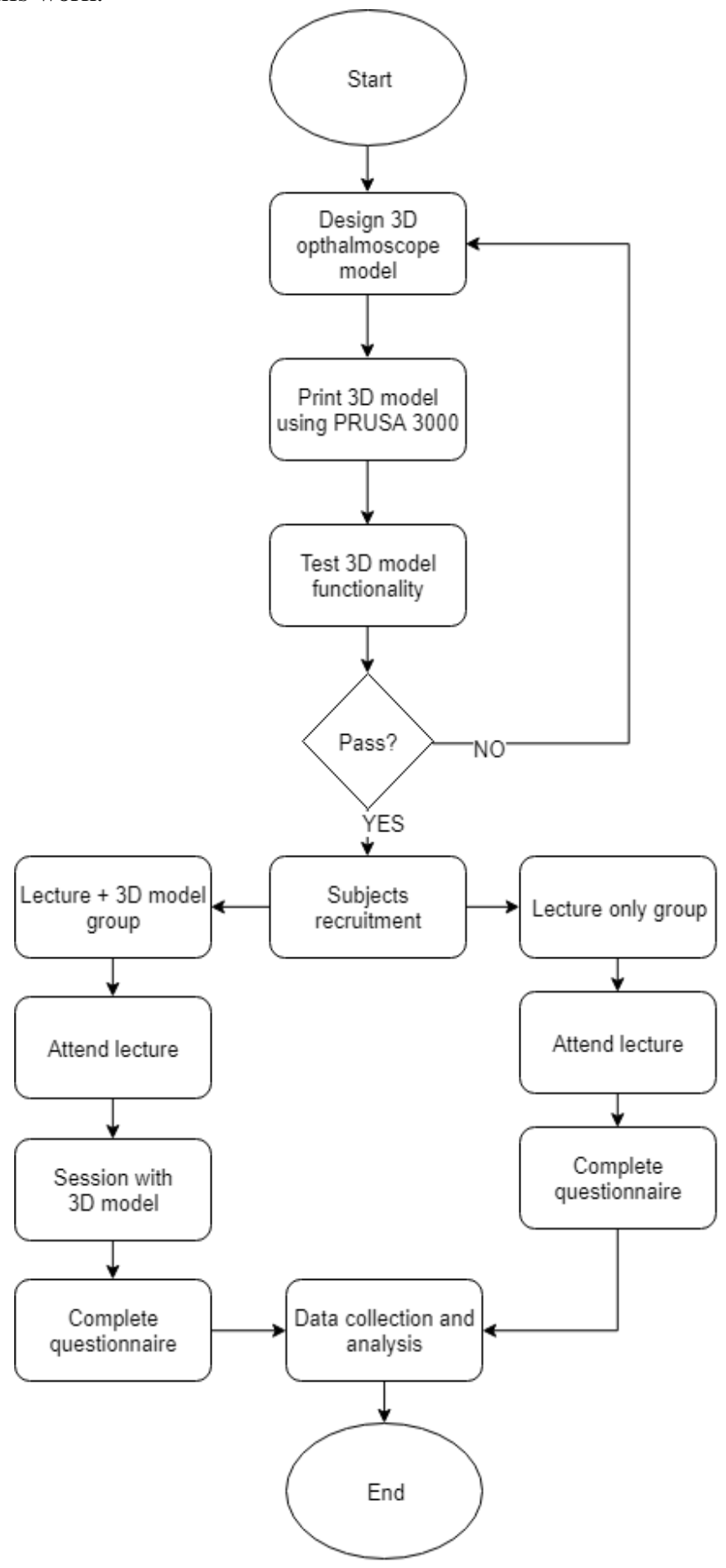

Fig. 2. Flowchart on study of students' confidence and enjoyment using 3D-printed device in optometric education.

Since there is no known published instructions about this type of experiment, the following instructions were developed and attached in the handout given to the students to ensure active participation with the $3 \mathrm{D}$ model:

- $\quad$ Place the 3D ophthalmoscope about 7-9 cm in front of eye model. Appreciate the 
inverted image of the axis scale on the eye model.

- Make sure the flashlight enters into pupil, for the best viewing result, the flashlight focuses on the left pupil.

- You might need a minor adjustment of distance to view the fundus.

- Record the video or take picture when you see the fundus.

- Try to identify optic disc, fovea and blood vessel.

- Please note that everything that you see in the fundus is inverted

The questions were asked to assess their confidence level were "I can visualize the structure of ophthalmoscope in lecture", "I can understand the general optical principles behind the ophthalmoscope" and "I can identify the structure of ophthalmoscopy".

Enjoyment level was assessed by following three positive statements, "stimulating to learn", "consider as revision tool in future" and "easy to understand", adapted from (Preece et. al, 2013). These three statements were assigned with 5-point Likert's scores which are; 1 for "strongly disagree", 2 for "disagree", 3 for "undecided", 4 for "agree" and 5 for "strongly agree".

The confidence and enjoyment levels were considered to be met when the scores are more than 3 .

\section{RESULTS}

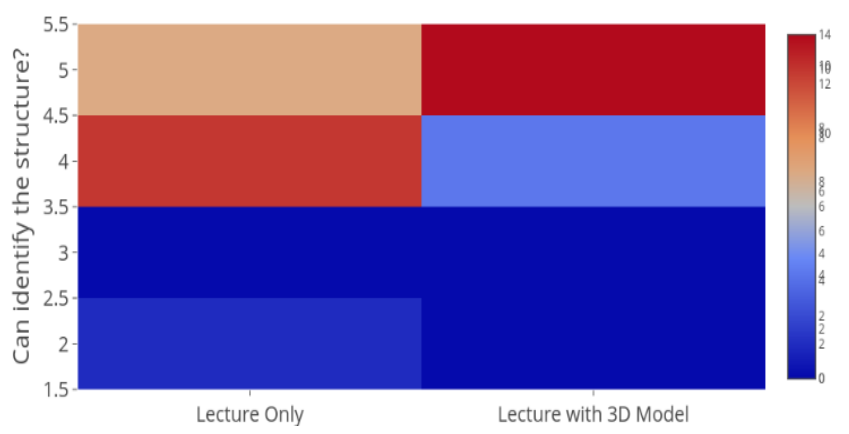

(a)

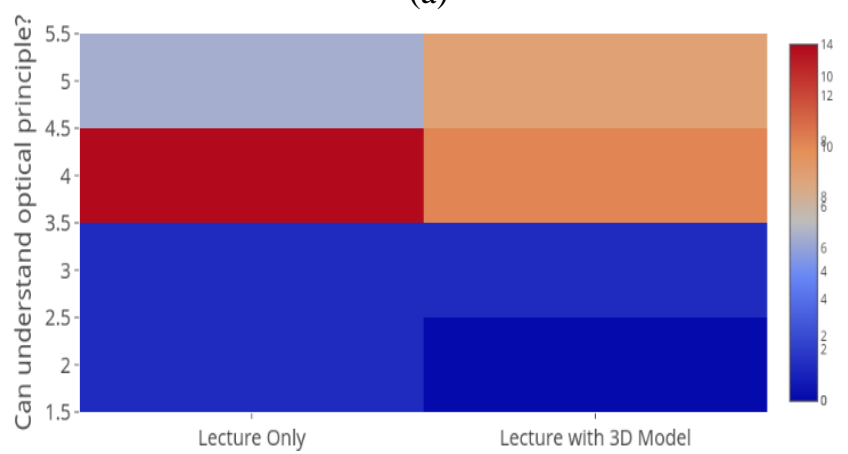

(b)

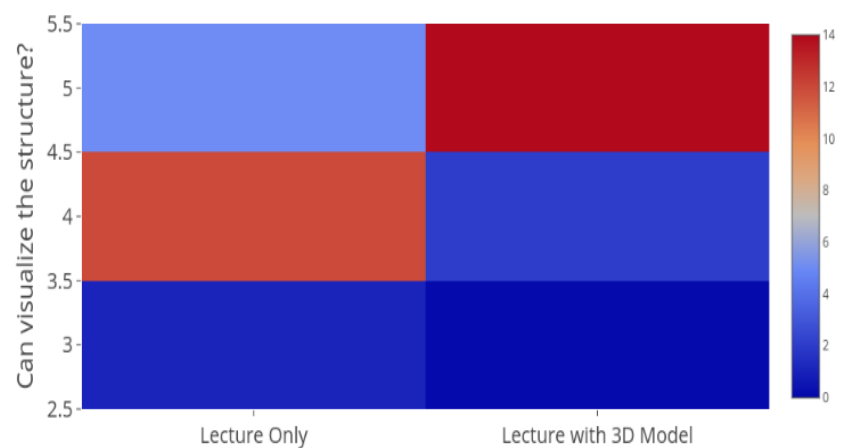

(c)

Fig. 3. Two-dimensional histogram showing the confidence level of participants when exposed to lecture only and with the combination of lecture and 3D model.

The results of the Likert's scores of 1 to 5 are presented in two-dimensional histogram. The hot colour (i.e. red) indicates higher number of participants agree to the statement. Conversely, the cool colour (i.e. blue) shows lower number of participants agree to the statement.

Figure 3 illustrates higher number of participants strongly agree that 3D model aids them in terms of identifying and visualizing the structure of the ophthalmoscope. More participants also shows strong agreement that the 3D model helps them in understanding the optical principle.

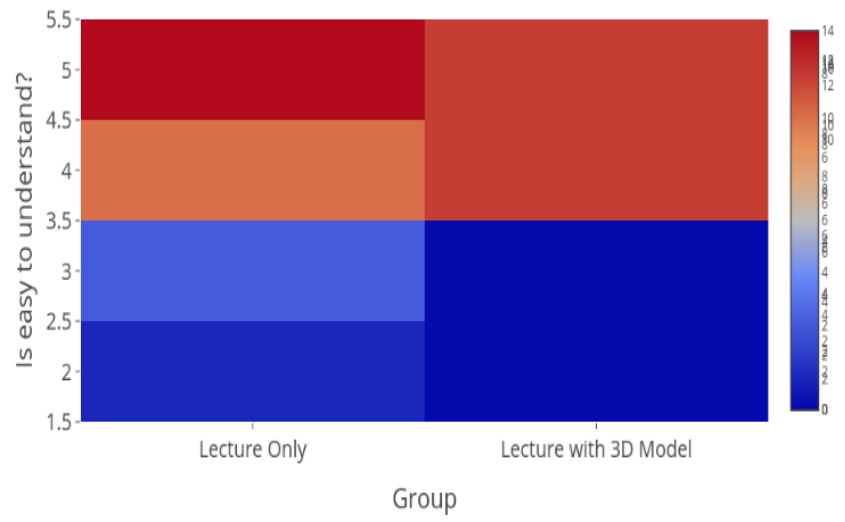

(a)

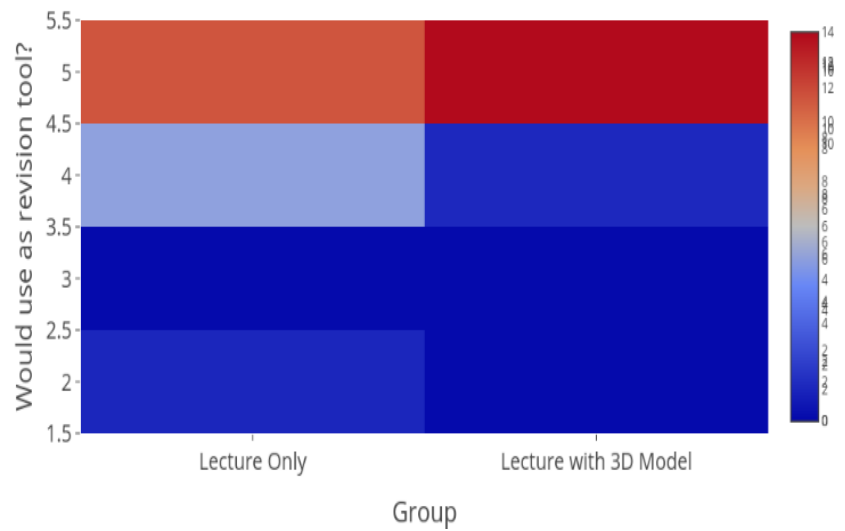

(b) 


\section{D-Printed Model Enhances Learning Experience in Optometric Education}

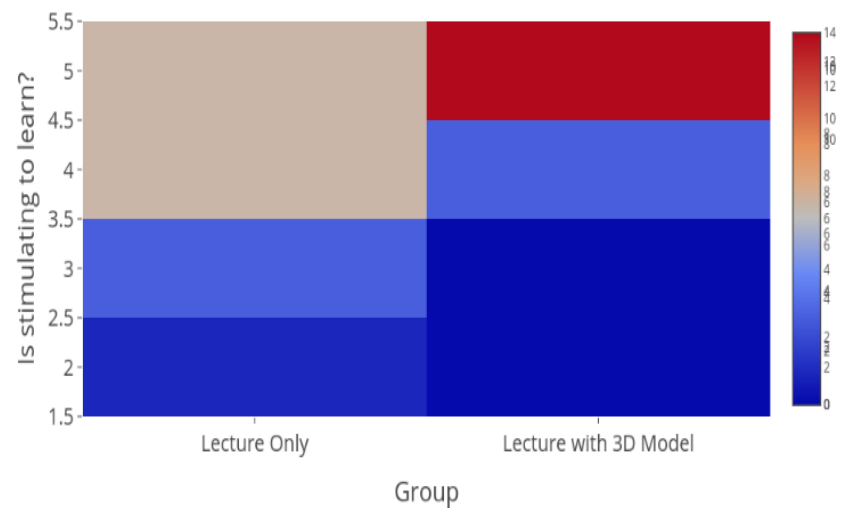

Fig. 4. Two-dimensional histogram showing the enjoyment level of participants when exposed to lecture only and with the combination of lecture and 3D model.

(c)

Table 1. The median score between "Lecture" and "Lecture with 3D Model" groups analysed by Mann-Whitney U test. confidence level as explained by Bengtsson, Persson \&

\begin{tabular}{|c|c|c|c|c|c|c|c|}
\hline & & $\begin{array}{l}\text { Help to } \\
\text { visualize }\end{array}$ & $\begin{array}{c}\text { Help to } \\
\text { understand }\end{array}$ & $\begin{array}{l}\text { Help to } \\
\text { identify } \\
\text { structure }\end{array}$ & Enjoyable and stimulating & As a revision tool & Easy to use \\
\hline & Mann-Whitney & & & & & & \\
\hline & $\mathrm{U}$ & 57 & 118 & 104 & 77 & 117 & 136 \\
\hline Lecture & Median & 4 & 4 & 4 & 4 & 5 & 4.5 \\
\hline Only & IQR & 1 & 1 & 1 & 1 & 1 & 1 \\
\hline $\begin{array}{l}\text { Lecture } \\
\text { with 3D }\end{array}$ & Median & 5 & 4 & 5 & 5 & 5 & 4.5 \\
\hline Model & IQR & 0 & 1 & 1 & 0 & 0 & 1 \\
\hline & $\mathrm{P}$-value & 0.001 & 0.31 & 0.119 & 0.008 & 0.243 & 0.8 \\
\hline
\end{tabular}

In Figure 4, consistent findings are detected when the participants were asked about all items related to enjoyment more participants strongly agreed that the 3D model stimulates the learning process and they would use it as a revision tool. However, majority of the participants $(n=16)$ did not show high preference with the statement that "it is easy to understand".

As shown in Table 1, the overall score between the two groups shows two items are statistically significant $(\mathrm{P}<0.05)$ - "Help to visualize" and "Enjoyable and stimulating".

\section{DISCUSSIONS}

The 3D-printed model is shown to supplement traditional lecture and could be used to augment the content with traditionally taught through textbooks (Preece et. al, 2013). The short time duration which is only an hour for student to explore the 3D-printed model also may affect their confidence level as it relates with exposure time, learning is a gradual process which requires time to build confidence. Besides that, the gender differences may affect the student's
Willenhag (2005) that men are much more confident compared to women especially in exam situation. This population has only 7 male subjects compared to 29 female subject that may affect the data analysis of the study.

The results found in this study is similar with the previous research done by Preece et al. (2013) stated that the 3D model group was significantly more positive response compared to learning textbook method. Moreover, students' enjoyment level can be affected with many factors. Al-Shara (2015) mentioned that the implementation of teaching aid must be interesting and attractive to learn include some sense of humor and respect the students also estimates their

perspective. This study can be improved in the future to create the enjoyment atmosphere by varying the color of $3 \mathrm{D}$ printed model to improve the enjoyment level in students.

The study is affected by the performance of the lecturer on delivering the lecture. The performance of the lecturer may be a confounding variable; thus, it may have created a bias in the analysis. Besides that, there is no analysis on 
students' learning styles and their academic background in this study which may give different outcome on their score. Other than that, the 3D-printed model of ophthalmoscope was hard to use as the illumination of viewer was not directly parallel to the user, as a result, the student may have taken longer time to view the fundus clearly. In addition, some of the students may not be competent enough to operate 3D-printed ophthalmoscope as they are have not entered the clinical session in this semester.

\section{CONCLUSIONS}

In conclusion, this study has demonstrated the positive effect of 3D-printed model in student's confidence and enjoyment levels among optometry students.

\section{ACKNOWLEDGMENT}

This research was supported by the Research Management Centre, International Islamic University Malaysia, under Research Initiatives Grant Scheme (RIGS)-Publication (P-RIGS 18-035-0035).

\section{REFERENCES}

1. M. N. Lee. (2002). Teacher education in Malaysia: Current issues and future prospects. Teacher education: dilemmas and prospects. 8(57).

2. M. N. Van den Berg, and W. H. A. Hofman, (2005). Student success in university education: A multi-measurement study of the impact of student and faculty factors on study progress. Higher education.50(3), 413-446.

3. J. C. Bernhard, S. Isotani, T. Matsugasumi, V. Duddalwar, A. J. Hung, E. Suer, and B. Hu. (2016). Personalized 3D printed model of kidney and tumor anatomy: a useful tool for patient education. World journal of urology. 34(3), 337-345.

4. L. Kiraly, M. Tofeig, N. K. Jha, and H. Talo. (2015). Three-dimensional printed prototypes refine the anatomy of post-modified Norwood-1 complex aortic arch obstruction and allow presurgical simulation of the repair. Interactive cardiovascular and thoracic surgery. 22(2), 238-240.

5. V. Waran, V. Narayanan, R. Karuppiah, D. Pancharatnam, H. Chandran, R. Raman, T. Z. Aziz. (2014). Injecting Realism in Surgical Training-Initial Simulation Experience With Custom 3D Models. Journal of Surgical Education. 71(2), 193-197.

6. K. H. A. Lim, Z. Y. Loo, S. J. Goldie, , J. W. Adams, and P. G. McMenamin. (2016). Use of 3D printed models in medical education: A randomized control trial comparing $3 \mathrm{D}$ prints versus cadaveric materials for learning external cardiac anatomy. Anatomical sciences education. 9(3), 213-221.

7. M. K. Oreilly, S. Reese, T. Herlihy, T. Geoghegan, C. P. Cantwell, R. N. Feeney, and J. F. Jones. (2015). Fabrication and assessment of 3D printed anatomical models of the lower limb for anatomical teaching and femoral vessel access training in medicine. Anatomical Sciences Education. 9(1), 71-79.

8. D. Preece, S. B. Williams, R. Lam, and R. Weller (2013). Lets Get Physical: Advantages of a physical model over 3D computer models and textbooks in learning imaging anatomy. Anatomical Sciences Education. 6(4), 216-224.

9. J. Al-Ramahi, H. Luo, R. Fang, A. Chou, J. Jiang, and T. Kille. (2016) Development of an innovative 3D printed rigid bronchoscopy training model. Annals of Otology, Rhinology \& Laryngology. 125(12), 965-969.

10. C. Bengtsson, M. Persson, and P. Willenhag. (2005). Gender and overconfidence. Economics letter. 86(2), 199-203.

11. I. Al-Shara. (2015). Learning and teaching between enjoyment and boredom as realized by the students: A survey from the educational field. European Scientific Journal, ESJ. 11(19).

\section{AUTHORS PROFILE}

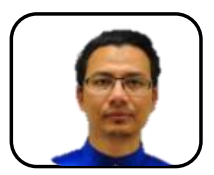

Mohd Zulfaezal Che Azemin, Doctor of Philosophy, Associate Professor, Kulliyyah of Allied Health Sciences, International Islamic University Malaysia.

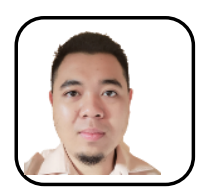

Mohd Afiq Ariffin Azman, Bachelor of Optometry (Hons.), Kulliyyah of Allied Health Sciences, International Islamic University Malaysia.

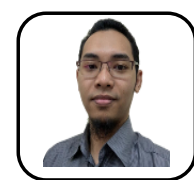

Muhammad Hafizuddin Bahrain, Bachelor of Optometry (Hons.), Kulliyyah of Allied Health Sciences, International Islamic University Malaysia.

Mohd Izzuddin Mohd Tamrin, Doctor of Philosophy, Assistant Professor, Kulliyyah of Information and Communication Technology, International Islamic
University Malaysia.

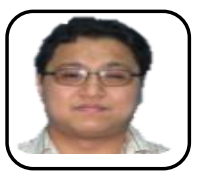

